\title{
Differential Impact of Audiogenic Stressors on Lewis and Fischer Rats: Behavioral, Neurochemical, and Endocrine Variations
}

\author{
David S Michaud', J McLean', Stephen E Keith', Catherine Ferrarotto', Shawn Hayley ${ }^{2,4}$, Samir A Khan ${ }^{3}$, \\ Hymie Anisman ${ }^{2,5}$ and Zul Merali*,3,4,5 \\ 'Consumer and Clinical Radiation Protection Bureau, Health Canada, Ottawa, Ontario, Canada; ${ }^{2}$ Institute of Neuroscience, Carleton University, \\ Ottawa, Ontario, Canada; ${ }^{3}$ School of Psychology, University of Ottawa, Ottawa, Ontario, Canada; ${ }^{4}$ Department of Cellular \& Molecular Medicine, \\ University of Ottawa, Ottawa, Ontario, Canada; ${ }^{5}$ Institute of Mental Health Research, Royal Ottawa Hospital, Ottawa, Ontario, Canada
}

\begin{abstract}
Exposure to intense noise can trigger a cascade of neuroendocrine events reminiscent of a stress response, including activation of the hypothalamic-pituitary-adrenocortical (HPA) axis. Using male Fischer and Lewis rats, which exhibit differences in their corticosterone response to stressors, this investigation assessed effects of acute noise exposure on neurochemical and neuroendocrine responses. In response to the noise exposure, Fischer rats displayed greater plasma adrenocorticotropin-releasing hormone (ACTH) and corticosterone responses than their Lewis counterparts. However, both strains responded with similar increases of plasma prolactin suggesting that strain differences in the HPA response were not likely because of differences in noise perception. Post-mortem analyses revealed that noise exposure induced strain-dependent variations of corticotropin-releasing hormone ( $\mathrm{CRH}$ ) across several brain regions. These effects were evident irrespective of whether the rats were noise exposed in a familiar (home cage) or unfamiliar environment. In vivo, dynamic assessment of immunoreactive (ir)- $\mathrm{CRH}$ at the pituitary gland revealed that noise exposure elicited an immediate rise in ir-CRH among Fischer rats, relative to the delayed response in Lewis rats. Similarly, the rise in local interstitial corticosterone was more rapid and pronounced in Fischer rats. In contrast to these differences, ir- $\mathrm{CRH}$ released at the central nucleus of the amygdala (CeA) was gradual and protracted following noise exposure in both strains. Behaviorally, the Fischer rats displayed an active stress response, whereas the Lewis strain adopted freezing as a defensive style. The role of $\mathrm{CRH}$ in the genesis of the overall straindependent response to stressors is discussed.

Neuropsychopharmacology (2003) 28, 1068-108I, advance online publication, 26 March 2003. doi: I0.1038/sj.npp. I 300। 49
\end{abstract}

Keywords: corticotropin-releasing hormone; fear-conditioning; microdialysis; push-pull perfusion; noise stressor

\section{INTRODUCTION}

In spite of its ubiquitous and intrusive nature, community noise has yet to be firmly established as a significant risk factor for the development of stress-related disease (WHO, 1999). Nevertheless, intense audio signals provoke neuroendocrine variations in humans and experimental animals reminiscent of those associated with stressor exposure, including increased circulating levels of adrenocorticotropin-releasing hormone (ACTH), glucocorticoids, and enhanced secretion of catecholamines, reflecting autonomic activation (Van Raaij et al, 1997; Windle et al, 1997). As hypothalamic corticotropin-releasing hormone (CRH) is the

*Correspondence: Dr Z Merali, Director General, Institute of Mental Health Research, I 45 Carling Ave., Lady Grey Bldg., Room 2043, Ottawa, Ontario, Canada KIZ 7K4, Tel: + I 613722 6521/655I, Fax: + | 613 722 587I, E-mail: merali@uottawa.ca

Received 21 June 2002; revised 02 January 2003; accepted 06 January 2003

Online publication: 10 January 2003 at http://www.acnp.org/citations/ Npp I 1003454 primary secretagogue for pituitary $\mathrm{ACTH}$, which in turn evokes the release of adrenal glucocorticoids, it seems likely that CRH contributes to the neuroendocrine effects of noise.

Several studies have demonstrated marked strain differences in response to physical and/or psychological stressors (Anisman et al, 1998; Dhabhar et al, 1997; Sternberg et al, 1992). In this respect, the Lewis rat has been extensively studied as a unique strain demonstrating susceptibility to various inflammatory conditions, including streptococcal cell wall-induced arthritis (Dhabhar et al, 1995; Sternberg et $a l, 1989 \mathrm{a}$ ) and encephalomyelitis (Mason et al, 1990). In contrast, the histocompatible Fischer strain is relatively resistant to the deleterious effects of stressor exposure (Dhabhar et al, 1993; Moncek et al, 2001; Sternberg et al, 1989b). In the current study we assessed the neuroendocrine, neurochemical, and behavioral responses to an acute audiogenic stressor in these two rat strains.

In addition to hypothalamic control over the activation of the hypothalamic-pituitary-adrenocortical (HPA) axis, considerable evidence sustains the notion that extrahypothalamic structures, such as the amygdala, may also 
regulate the activation of the $\mathrm{HPA}$ axis. Indeed, lesions to the CeA block the HPA responses to acoustic stimuli (Feldman et al, 1994) and restraint stressors (Van de Kar et al, 1991). Furthermore, the stressor-induced increase of CRH mRNA and release at the CeA (Hsu et al, 1998; Merali et al, 1998; Pich et al, 1995; Richter et al, 2000) suggests that previously observed HPA, autonomic, and behavioral responses to stressors in the Fischer and Lewis rats (Glowa et al, 1991; Sternberg et al, 1989a, 1992) might be associated with differences in the release dynamics of $\mathrm{CRH}$ at the CeA. In the present investigation, we determined whether their differential sensitivity would be restricted to HPA factors and/or include extrahypothalamic sites. In addition to immediate effects, we also examined whether noise exposure would induce relatively protracted changes of neuroendocrine and neuropeptide activity in these strains, and whether such effects would be influenced by the environmental context in which the stressor was applied. Although stressor effects are usually transient (Anisman et al, 1991), the duration of these effects can be influenced by contextual cues, in this instance administering the stressor in an animal's home cage, as opposed to a similar but novel cage.

In the present investigation, we assessed immunoreactive (ir)-CRH levels in post-mortem brain micropunched tissue of Lewis and Fischer rats that had been exposed to noise. Although micropunch results provide useful information regarding which brain regions may be involved in the stress response, they preclude conclusive interpretations regarding the temporal dynamics associated with the challenge. Therefore, we complemented the post-mortem studies with experiments that assessed interstitial levels using in vivo microdialysis and push-pull perfusion, hence providing a more dynamic and clearer mechanistic perspective.

\section{MATERIALS AND METHODS}

\section{The Effect of Noise Exposure on Brain ir-CRH} and Plasma Hormone Levels

Animals. Male Lewis and Fischer rats (Charles River, Canada), weighing 300-350 g were used. The animals were housed individually in standard rodent cages $\left(36 \times 31 \times 17 \mathrm{~cm}^{3}\right)$ with a $12: 12 \mathrm{~h}$ reversed light-dark cycle (lights off 07:00 h) and temperature maintained at $23-24^{\circ} \mathrm{C}$ with $60 \%$ relative humidity. Animals had ad libitum access to Purina ${ }^{\mathrm{T}}$ rat chow and tap water. All experimental procedures met the guidelines on the ethical treatment of animal subjects in experimental research set forth by the University of Ottawa and Health Canada.

Noise exposure and blood collection. To minimize the effects of transporting animals from the housing room to the test area, rats were acclimated to the regimen of daily transportation for 3 weeks prior to the experiment being initiated. On test days (between 08:00 and 12:00 h), animals were transported (in their home cages), from the housing area to a separate room where they were immediately exposed to a 15-min burst of $90 \mathrm{~dB}$ continuous white noise, band-limited from $80 \mathrm{~Hz}$ to $20 \mathrm{kHz}$, and equalized in $1 / 3-$ octave bands within the cage. Noise was delivered through two professional loud speakers (JBL4892) suspended $\sim 40 \mathrm{~cm}$ above the testing cages. Sound pressure level varied slightly, depending on the position in the cage and the arrangement of bedding chips. Based on measurements from 10 positions within the cage and variations in bedding distribution, overall the standard deviation for the unweighted average sound level was $\pm 2 \mathrm{~dB}$, and in individual $1 / 3$-octave bands it was $\pm 4 \mathrm{~dB}$.

Animals were killed (by decapitation) either immediately $(\sim 30 \mathrm{~s})$ after the stressor session (ie $15 \mathrm{~min}$ after noise/no noise onset; $n=9 /$ strain/condition) or were returned to their home cages, and then killed $1 \mathrm{~h}$ later $(n=9 /$ strainnoise; $n=7 /$ strain-no noise). Control rats were treated identically, except that the noise exposure was not administered. Brains and trunk blood were collected for radioimmunoassay (RIA) of peptide and hormone content (Palkovits and Brownstein, 1988).

\section{The Impact of Environmental Cues on Protracted Changes of Brain ir-CRH and Plasma Hormone Levels $24 \mathrm{~h}$ after Noise Exposure}

Animals and procedure. Rats of each strain were brought to the test room, where half of the rats remained in their home cages $(n=10 /$ strain), while the remaining rats were placed in a similar cage that contained fresh bedding (novel cage, $n=10 /$ strain). The rats were then exposed to the noise stressor as described earlier. Animals exposed to noise in a novel cage were returned to their home cages immediately after noise exposure and all rats were returned to the housing room. Thus, some rats were maintained in the same environment as that in which they were ordinarily housed, while the remaining rats were exposed to noise in a novel environment and then returned to their home cages before returning to the housing room. The following day $(24 \mathrm{~h}$ after noise termination) rats were transported to the necropsy area where they were killed immediately and brains and trunk blood taken for later neurochemical and neuroendocrine determinations.

Tissue collection. Following decapitation, brains were rapidly removed and placed into a brain matrix (McIntyre, Carleton University, ON) with coronal planes corresponding to the rat brain atlas of Paxinos and Watson (1986). Serial coronal sections $(1.5-2.0 \mathrm{~mm})$ were obtained and placed in ice-cold $0.1 \mathrm{M}$ phosphate-buffered saline and a total of 11 discrete brain nuclei known to be sensitive to the effects of stressors were identified and micropunched/ dissected. The selected hypothalamic areas included the paraventricular nucleus of the hypothalamus (PVN), and the median eminence-arcuate complex (Me/Arc). In addition, the following extrahypothalamic regions were taken: paraventricular thalamic nucleus (PV), prefrontal cortex (PFC), nucleus accumbens (nAcb), caudate (Cau), dorsal hippocampus (dHipp), central nucleus of the amygdala (CeA), basal lateral nucleus of the amygdala (BLA), medial nucleus of the amygdala (MeA), and locus coeruleus (LC). All nuclei were bilaterally micropunched using a customized $1 \mathrm{~mm}$ punch, except for the Me/Arc and PV, which were removed with a single punch, while the dHipp and PFC were microdissected free-hand (see Figure 1). Brain tissue was placed in clean $1.5 \mathrm{ml}$ centrifuge tubes on dry ice and stored at $-80^{\circ} \mathrm{C}$ until processing (within 4 weeks). All samples were collected between 07:00 and 13:00 h. 


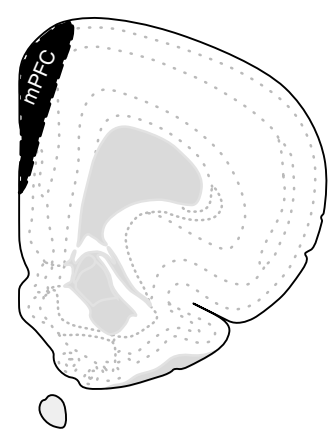

$5.83 \mathrm{~mm}$

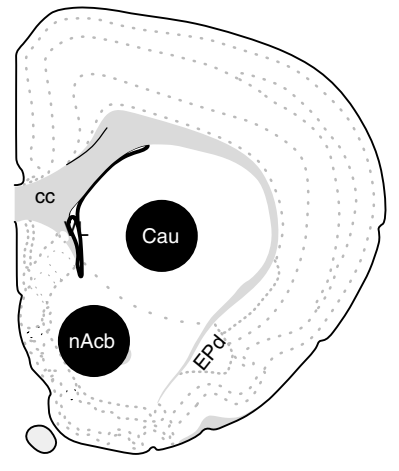

$6.83 \mathrm{~mm}$

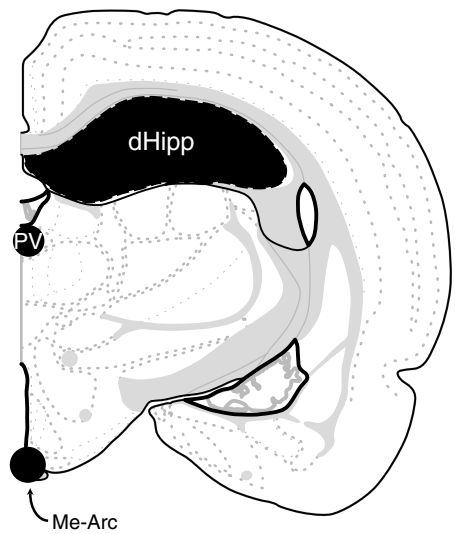

$10.91 \mathrm{~mm}$

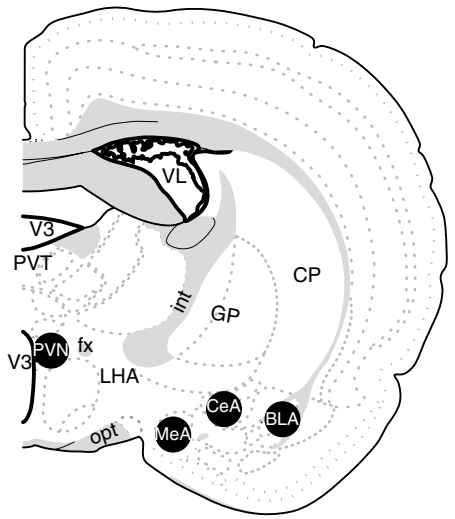

$9.31 \mathrm{~mm}$

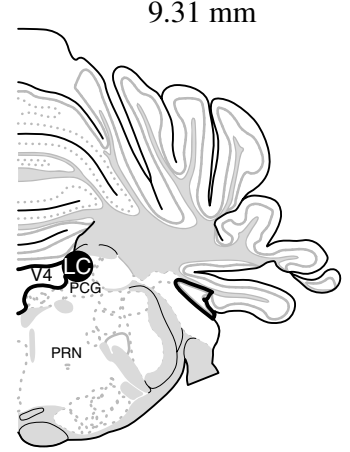

$16.07 \mathrm{~mm}$

Figure I Fresh brains were blocked in an acrylic rat brain matrix and $1.5-2.0 \mathrm{~mm}$ coronal sections taken. A series of discrete brain regions were bilaterally punched or free-hand dissected according to the atlas of Paxinos and Watson (1986). Selected brain regions are demarcated with solid shading at the anterior pole of each site. Distances from bregma are indicated below each section. Abbreviations: BLA, basal lateral amygdala; CeA, central amygdala; Cau, caudate; dHipp, dorsal hippocampus; MeA, medial amygdala; Me-Arc, median eminence arcuate complex; nAcb, nucleus accumbens; PFC, prefrontal cortex; PV, paraventricular thalamic nucleus; PVN, paraventricular nucleus of the hypothalamus; LC, locus coeruleus.

Tissue processing. Tissue punches were sonicated (VirSonic 60 , Virtus, USA) in $0.5-1.0 \mathrm{ml}$ of Iscove's modified Dulbecco's buffer (GIBCO) containing $0.5 \%$ fetal calf serum and a cocktail enzyme inhibitors (in mM: 100 amino- $n$ caproic acid, 10 EDTA, 5 benzamidine- $\mathrm{HCl}$, and 0.2 phenylmethylsulfonyl fluoride) for $10 \mathrm{~s}$. A portion of the homogenate $(25 \mu \mathrm{l})$ was then withdrawn for protein determination, and the remainder of the homogenate was centrifuged at $13000 \mathrm{rpm}$ at room temperature for $9 \mathrm{~min}$. Supernatant was aliquoted into $0.6 \mathrm{ml}$ vials and stored at $-80^{\circ} \mathrm{C}$ for subsequent peptide level determination. Protein assays were performed using bicinchoninic acid with a protein analysis kit (Pierce Scientific, Brockville, ON) using the microtiter plate method.

Plasma ACTH, corticosterone, and prolactin detection. Trunk blood was collected into $5.0 \mathrm{ml}$ glass tubes containing EDTA (Fischer Scientific Ltd, ON), centrifuged at $1500 \mathrm{rpm}$, and the plasma aliquoted into $1.5 \mathrm{ml}$ vials and stored at $-80^{\circ} \mathrm{C}$. Plasma $\mathrm{ACTH}$, corticosterone, and prolactin levels were determined, in duplicate, using commercial RIA kits (ICN Pharmaceuticals Inc., Costa Mesa, CA). These assays yielded intra- and interassay variations of less than $10 \%$. The quantification of corticosterone in the perfusates was accomplished using a modification of the commercially available corticosterone RIA protocol designed to enhance the sensitivity of the assay (Bonsall et al, 1996).

\section{The Effect of Noise Exposure on the Release of ir-CRH at the $\mathrm{CeA}$}

Animals and surgical procedure. Male Lewis $(n=8)$ and Fischer $(n=9)$ rats were maintained as described above. Rats were anesthetized $(60 \mathrm{mg} / \mathrm{kg}$ i.p. pentobarbital) and stereotaxically implanted with a 20 -gauge stainless-steel guide cannula containing a removable 24-gauge stainlesssteel obturator aimed at the dorsal aspect of the CeA. The placement coordinates (Paxinos and Watson, 1986) with skull level were anteroposterior, $-2.3 \mathrm{~mm}$; dorsoventral, $-7.0 \mathrm{~mm}$; and lateral, $\pm 4.2 \mathrm{~mm}$. The guide cannula protruding from a custom-manufactured Delrin ${ }^{\circledR}$ pedestal was secured to the skull with four stainless-steel screws and dental cement. After surgical recovery (at least 7 days), animals were transferred to individual testing chambers and allowed to acclimate for $48 \mathrm{~h}$ before testing. The testing chambers comprised Plexiglas cages $\left(25 \times 35 \times 34 \mathrm{~cm}^{3}\right)$ with a stainless-steel grid floor.

In vivo microdialysis. Approximately $24 \mathrm{~h}$ prior to testing, rats were lightly restrained manually $(\sim 20 \mathrm{~s})$, and the obturator within the guide cannula was replaced with a 
concentric microdialysis probe, consisting of a $2.0 \mathrm{~mm}$ regenerated cellulose active membrane $(250 \mu \mathrm{m}$ outer diameter; 6000 molecular weight cutoff; Spectrum Laboratories, CA). The probe was partially inserted so that the active membrane remained within the guide cannula shaft. On the following day, the anchor screw securing the probe was loosened and the probe was gently inserted into the $\mathrm{CeA}$ of the freely behaving animals. Each probe was resecured with the anchor screw and connected via polyethylene tubing (Intermedic, Clay Adams, NJ) to a liquid swivel (Instech Laboratories, PA) and a $2.5 \mathrm{ml}$ gastight infusion syringe attached to a pump (model 22, Harvard Apparatus, MA). Microdialysis probes were perfused at $3 \mu \mathrm{l} / \mathrm{min}$ with filtered Kreb's-Ringer phosphate (KRB) solution consisting of (in $\mathrm{mM}$ ): $2.7 \mathrm{~K}^{+}, 145 \mathrm{Na}^{+}$, $1.35 \mathrm{Ca}^{2+}, 1.0 \mathrm{Mg}^{2+}, 150 \mathrm{Cl}^{-}, 0.05$ ascorbate, $\mathrm{pH} 7.4$ (Moghaddam and Bunney, 1989), and BSA (0.1\%). After the probe insertion, a 60-min stabilization period was allowed, which represented a time interval previously demonstrated to permit stabilization of peptide release (Merali et al, 2001). Subsequently, dialysate samples were collected every $20 \mathrm{~min}(\sim 60 \mu \mathrm{l})$ and immediately frozen on dry ice and stored at $-80^{\circ} \mathrm{C}$ for 2 weeks until RIA analyses. The efficiency of in vitro peptide recovery by the microdialysis probes averaged $3.3 \pm 0.6 \%$ (details previously described by Merali et al, 1998).

Noise exposure. Following the collection of six baseline dialysate samples, a single 15-min burst of $90 \mathrm{~dB}$ continuous white noise (as described previously) was delivered via speakers (Voxtek $85 \mathrm{~S}, 8 \Omega 0.5 \mathrm{~W}$ ) affixed to the top of the test cage. Following noise exposure, 12 postnoise dialysate samples were collected.

\section{The Effect of Noise Exposure on ir-CRH and Corticosterone Availability at the Anterior Pituitary}

Animals and surgical procedure. Male Lewis $(n=9)$ and Fischer $(n=12)$ rats, maintained as previously described, were anesthetized with pentobarbital $(60 \mathrm{mg} / \mathrm{kg}$ i.p.) and stereotaxically implanted with a 20-gauge custom-made stainless-steel guide cannula containing a removable 24gauge stainless-steel obturator aimed at the anterior lobe of the pituitary gland. The placement coordinates (Paxinos and Watson, 1986) with skull level were anteroposterior, $-5.3 \mathrm{~mm}$; dorsoventral, $-11.0 \mathrm{~mm}$; and lateral, $\pm 0.9 \mathrm{~mm}$. The guide cannula was secured to the skull with four stainless-steel screws and dental cement. After surgical recovery (at least 7 days), animals were transferred to individual testing chambers and allowed to acclimate for $24 \mathrm{~h}$ before being placed individually in the noise room, where they remained for another $24 \mathrm{~h}$ prior to testing. Rats were tested individually in test chambers identical to those used in the microdialysis experiments.

In vivo push-pull perfusion. Push-pull probes were custom manufactured using a 24-gauge stainless-steel outer cannula as the 'pull' aspect of the probe, while a concentric silica tubing $(75 \mu \mathrm{m}$ ID $\times 150 \mu \mathrm{m}$ OD, Polymicro Technologies, AZ) protruding $0.4 \mathrm{~mm}$ beyond the outer cannula constituted the 'push' element of the probe. On the morning of testing the probes were calibrated for $20 \mathrm{~min}$ ex vivo to ensure the stability of the push-pull dynamics. The obturator was then carefully removed from the guide cannula of freely moving rats and replaced with the probe so that the silica tubing entered into the anterior lobe of the pituitary gland (permitting a free exchange between the $\mathrm{KRB}$ and the interstitial fluid). Push-pull probes were secured with polyethylene tubing to a dual channel liquid swivel (Instech Laboratories, PA) and then connected to separate peristaltic pumps (Minipulse 3, Gilson, WI) that were used to perfuse the probes with KRB (as described above). Typically, the 5-min sampling interval yielded $110 \mu \mathrm{l}$ of perfusate, which was aliquoted into two separate sample vials. These were immediately placed on dry ice and later stored at $-80^{\circ} \mathrm{C}$ until $\mathrm{CRH}$ and corticosterone assays were conducted, 2-3 weeks later.

Noise exposure. Following the insertion of the probe 12 baseline samples were collected (over a $1 \mathrm{~h}$ period), followed by a 15-min burst of $90 \mathrm{~dB}$ continuous white noise identical to that described in the previous experiments. In all, three $5 \mathrm{~min}$ samples were collected during noise exposure followed by an additional 12 postnoise samples.

\section{Strain-Dependent Behavioral Response to Noise Exposure}

Behavioral monitoring. During the push-pull experiment, the occurrence of various behaviors was assessed using a time-sampling procedure (Merali and Banks, 1994). Specifically, during the 15 -min period prior to noise onset, during the 15-min noise exposure period, and for an equivalent time following noise termination, the occurrence of a predefined behavior(s) was recorded during each 5-s observation interval. The cumulative frequency for each of the following behaviors is reported for each 15-min observation interval. Sleeping/resting: lying still with eyes completely or partially closed; exploration: actively moving about the cage; sniffing: vibrissal movements accompanied by head movements directed toward the floor or walls of the chamber; rearing: forelimbs off the cage floor in the absence of grooming; grooming: forelimbs are wiped over the face or ventral regions of abdomen and thorax; freezing: rigid posture, complete absence of visible movement, including vibrissae, with rapid respiration (Goldstein et al, 1996; Horvitz et al, 2001). In our laboratory, this procedure had previously been found to yield better than $90 \%$ agreement between raters (Merali and Banks, 1994).

Histology. At the end of the microdialysis and push-pull studies, animals were briefly anesthetized with halothane and then killed so that their brains could be extracted, sectioned, and stained for histological verification of probe placement. The correct placement of the push-pull probe into the anterior lobe of the pituitary gland was readily verified in the freshly extracted whole pituitary gland using low magnification without staining. Only data from correctly placed probes were used for statistical analyses.

RIA. The detection and quantification of ir-CRH was achieved using a solid-phase high-sensitivity adaptation or modification (Maidment and Evans, 1991) of the doubleantibody liquid phase RIA originally described by Vale et al 
(1983). Briefly, protein A/G- (Calbiochem Corp., CA) coated immulon-4 wells (Dynatec Laboratories Inc., VA) were incubated with anti-CRH serum ( $\mathrm{rC70}$, kindly provided by $\mathrm{W}$ Vale, The Salk Institute, La Jolla, CA) for $2 \mathrm{~h}$ at $20^{\circ} \mathrm{C}$. Samples, standards (diluted in tissue-processing medium, ranging from 0.05 to $250 \mathrm{fmol} /$ well), and blanks were incubated for $24 \mathrm{~h}$ at $4{ }^{\circ} \mathrm{C}$. Next, $25 \mu \mathrm{l}$ of assay buffer containing $5000-6000 \mathrm{cpm}$ of ${ }^{125} \mathrm{I}-\left[\mathrm{Tyr}^{0}\right]$-rCRF (Amersham, $\mathrm{ON})$ was added to each well and incubated for an additional $18 \mathrm{~h}$ at $4^{\circ} \mathrm{C}$. Finally, the wells were rinsed and separated, and their residual radioactivity was counted in a gamma counter (Cobra II Auto gamma, Model D5002, Packard Instrument Company, CT). A four-parameter logistic curve fit model was used for interpolation of the standard curve. Sensitivity of the assay was typically $\sim 0.1 \mathrm{fmol} /$ well.

Statistical analyses. All results are expressed as means \pm SEM. The plasma ACTH, corticosterone and prolactin levels, and the brain tissue levels of CRH were analyzed by a series of 2 (Strain) $\times 2$ (Noise condition) $\times 2$ (Time: immediate $v s 1 \mathrm{~h}$ ) analyses of variance (ANOVA). Similarly, the data from rats killed 24-h postnoise exposure in their home $v s$ novel cage were analyzed by a 2 (Strain) $\times 2$ (Stressor condition: home cage $v s$ novel environment) ANOVA. Subsequent comparisons of means of significant main effects or simple effects of significant interactions were analyzed using Bonferroni corrected $t$-tests. At times, the degrees of freedom varied because of missing samples.

For the analysis of the in vivo microdialysis and pushpull results, ir-CRH and corticosterone release, the 3 baseline values preceding noise exposure from each animal were averaged and defined as $100 \%$. All values were then expressed as a percentage of that baseline value. A significant main effect of Sample was followed up with Bonferroni corrected $t$-tests at relevant sample points. For the behavioral data obtained during the push-pull study, separate mixed measures ANOVAs with Sample blocks (baseline, noise, and postnoise) as the within-group variable were performed for each behavior, with Strain (Fischer vs Lewis) serving as the between-group factor.

\section{RESULTS}

\section{Strain-Dependent Behavioral Response to Noise Exposure}

Figure 2 depicts the behavior of rats at baseline, during noise exposure, and postnoise. These behavioral data were collected in the push-pull study but are presented first to illustrate the robust strain-dependent behavioral effects of the stressor. Individual ANOVAs of the frequency of sniffing, grooming, and exploration revealed significant Strain $\times$ Sample Blocks interactions, $F^{\prime} s_{(2,38)}=11.41,8.95$, and 9.91, $p$ 's $<0.001$, respectively. Post hoc analyses revealed that sniffing, grooming and exploration were significantly elevated from baseline during noise exposure in the Fischer, but not in the Lewis rats (see Figure $2 \mathrm{a}-\mathrm{c}$ ). In each instance, these behaviors in the Fischer rats were significantly more frequent than in the Lewis rats during the noise period.

Freezing varied as a function of the interaction between Strain and Sample Blocks, $\mathrm{F}_{(2,38)}=14.15, p<0.001$, that was because of a marked increase of immobility during noise

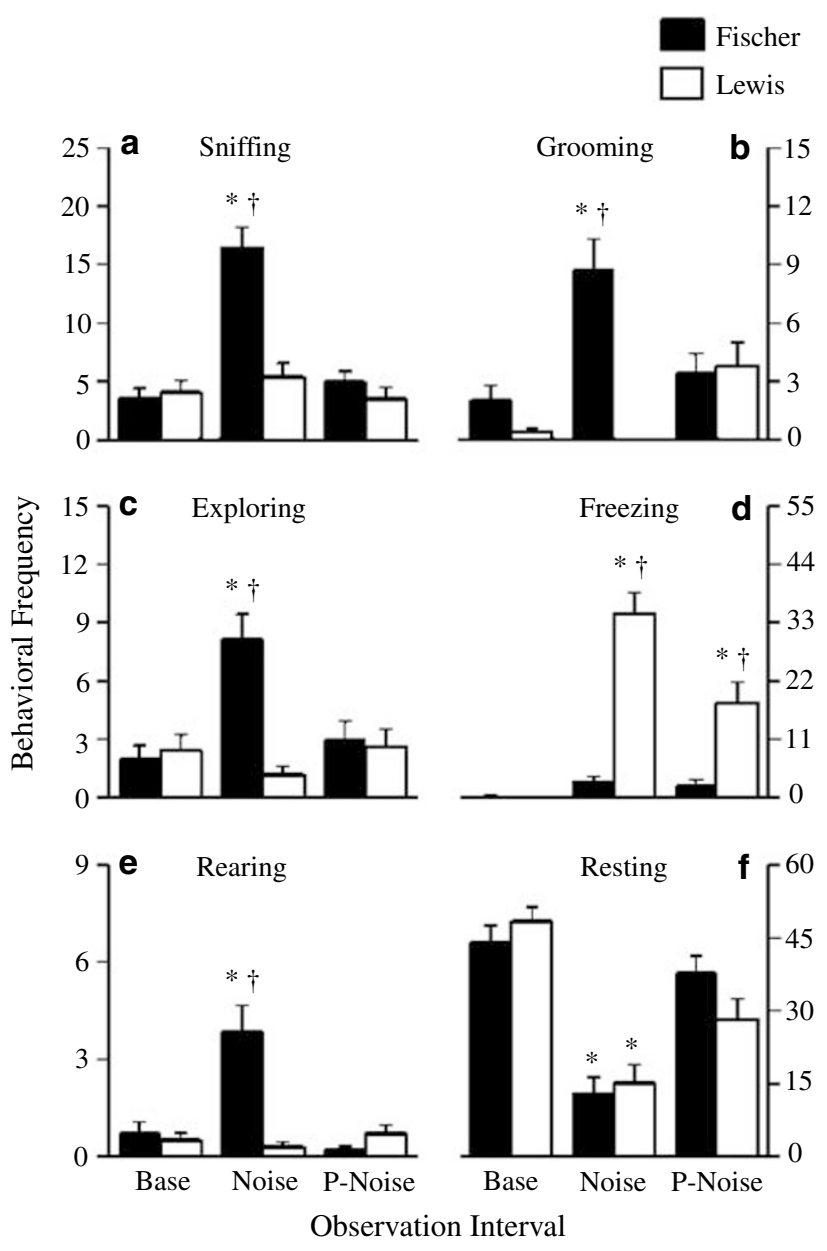

Figure 2 The frequency of sniffing (a), grooming (b), exploring (c), freezing (d), rearing (e), and resting ( $f$ ) was observed before noise exposure (base) during noise exposure (noise) and following $15 \mathrm{~min}$ of noise exposure (P-noise) in Fischer and Lewis rats. *Significant within-strain difference from baseline condition, $p<0.05$. 'Significant between strain difference from matched time observation period, $p<0.05$

exposure in the Lewis rats (see Figure 2d). The elevated levels of freezing were still evident during the postnoise period. As a result, during the noise and the postnoise period, freezing in the Lewis rats significantly exceeded that in the Fischer rats. Strain $\times$ Sample Blocks interactions were also evident for rearing, $\left.\mathrm{F}_{(2,38)}=14.28, p<0.000\right)$, and resting, $F_{(2,38)}=3.33, p<0.05$. Post hoc analyses indicated that while both strains showed almost no rearing during baseline, this behavior increased significantly with noise exposure only in the Fischer rats (see Figure 2e,), resulting in a more frequent rearing than in the Lewis strain. The Strain $\times$ Sample Blocks interaction for resting derived from a slightly higher amount of resting following noise exposure among the Fischer rats (see Figure 2f).

\section{The Effect of Noise Exposure on Brain ir-CRH and Plasma Hormone Levels}

Figure 3a depicts the changes of plasma ACTH associated with noise exposure. The ANOVA revealed that ACTH levels varied as a function of the Noise $\times$ Time and the 

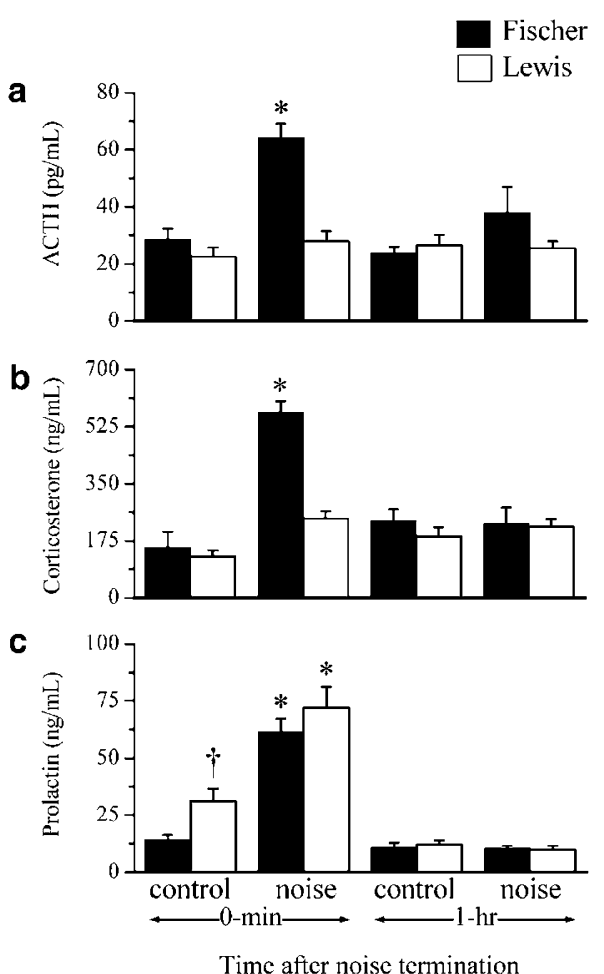

Figure 3 Variations of plasma hormone levels at $0 \mathrm{~min}$ and $\mathrm{I} \mathrm{h}$ after 15 min of noise exposure are depicted as means ( \pm SEM) for ACTH (a), corticosterone (b), and prolactin (c). *Significant within-strain difference from matched time control group, $p<0.000 \mathrm{I}$. 'Significant between strain difference at matched time, $p<0.05$.

Noise $\times$ Strain interactions, $\quad F^{\prime} s_{(1,60)}=4.37$ and 5.96, p's $<0.05$, respectively. The comparisons of the means comprising the simple effects of these interactions confirmed that immediately after noise exposure the ACTH concentrations were elevated in the Fischer rats but not in the Lewis strain. Within $1 \mathrm{~h}$ of stressor termination ACTH levels in the Fischer rats had returned to control levels. The effects of the noise exposure on plasma corticosterone levels essentially paralleled the ACTH changes (see Figure $3 \mathrm{~b}$ ). The ANOVA revealed a significant Strain $\times$ Noise $\times$ Time interaction, $\mathrm{F}_{(1,60)}=11.36, p<0.01$. The multiple $t$-tests indicated that corticosterone levels were elevated in Fischer rats immediately after noise exposure, but not at the $1 \mathrm{~h}$ interval. In the Lewis rats, in contrast, the noise stressor failed to alter significantly corticosterone levels.

Figure $3 \mathrm{c}$ shows that basal plasma prolactin in Lewis rats was slightly, but significantly, higher than in the Fischer rats, $\mathrm{F}_{(1,60)}=4.57, p<0.05$. As well, prolactin levels varied as a function of the Noise $\times$ Time interaction, $\mathrm{F}_{(1,60)}=45.89, p<0.01$. Unlike ACTH and corticosterone, the level of prolactin was comparably elevated in both strains immediately after the noise exposure. In plasma taken $1 \mathrm{~h}$ later, prolactin had returned to basal levels.

Hypothalamic-pituitary ir-CRH variations following noise exposure. Figure 4 shows the changes of ir- $\mathrm{CRH}$ within the PVN (upper panel) and Me-Arc (lower panel). At the PVN the levels of ir-CRH varied as a function of the Noise $\times$ Time interaction, $\mathrm{F}_{(1,50)}=16.14, p<0.001$. Immediately after the noise exposure, ir-CRH was slightly

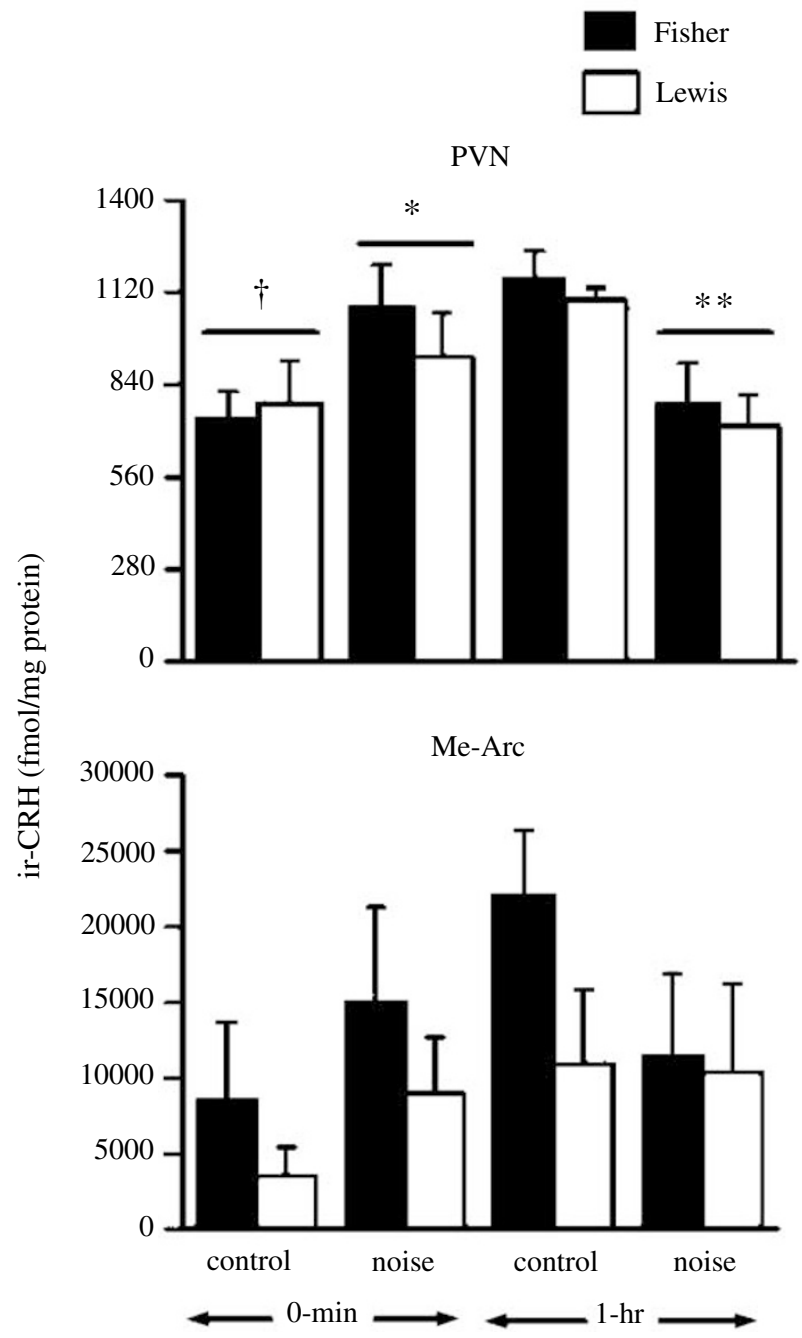

Time after noise termination

Figure 4 Variations of ir-CRH tissue levels (mean $\pm \mathrm{SEM}$ ) at 0 min and I h after I 5 min of noise exposure at the PVN (upper panel), and Me-Arc (lower panel). PVN, paraventricular nucleus of the hypothalamus; Me-Arc, median eminence-arcuate complex. *, **Significant difference from matched time control group, $p<0.05$ and 0.01 , respectively. 'Significant difference from I-h time point, $p<0.05$.

elevated in both strains, although this effect was marginal in the Lewis strain. In noise-exposed rats killed $1 \mathrm{~h}$ later, irCRH levels were lower than among nonstressed controls. The latter effect was because of a significant increase of ir$\mathrm{CRH}$ in control animals killed at the $1 \mathrm{~h}$ interval, relative to control groups killed at the earlier time point (see Figure 4, upper panel). There was a tendency for the ir-CRH levels at the Me-Arc to be higher in the Fischer rats; however, because of the high variability, these effects failed to reach statistical significance (see Figure 4, lower panel).

Variations of ir-CRH levels at amygdaloid nuclei following noise exposure. Figure 5 represents changes in the content of ir-CRH at the amygdala. The ir-CRH changes at the CeA varied as a function of a significant Noise $\times$ Time interaction, $F_{(1,48)}=21.18, p<0.01$. In both strains, the level of ir-CRH immediately after stressor exposure did not differ from that of controls. However, $1 \mathrm{~h}$ after noise exposure the 


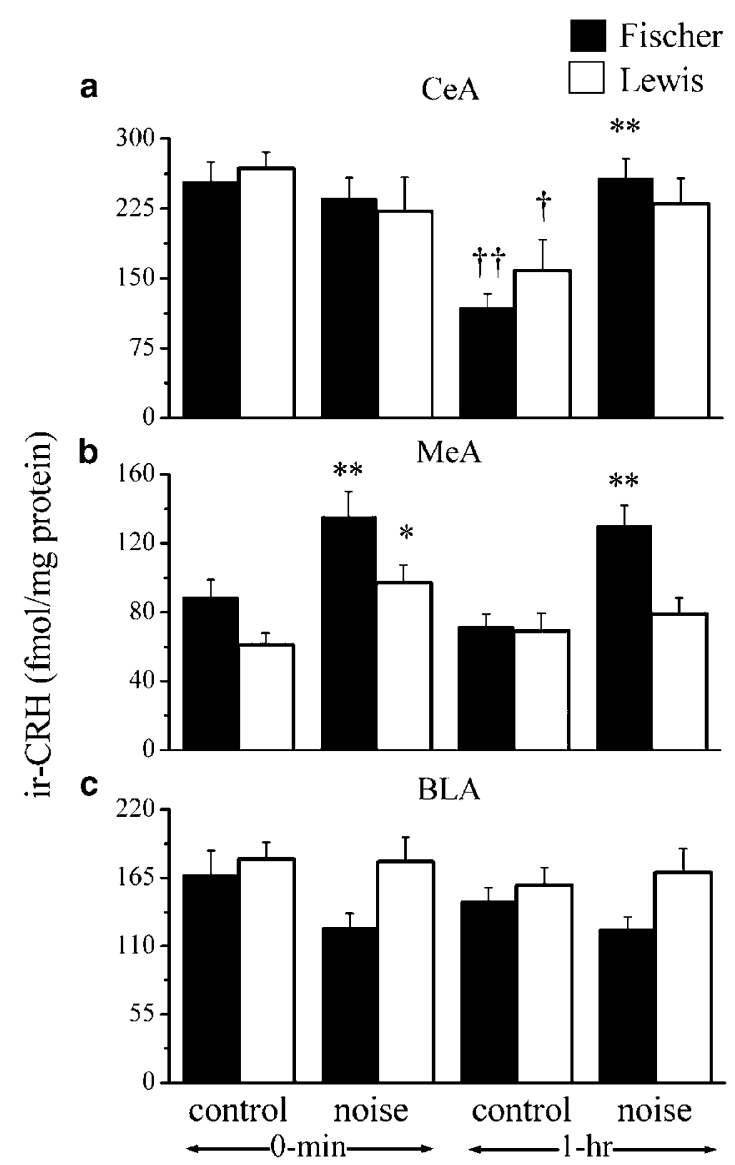

Time after noise termination

Figure 5 Variations of ir- $\mathrm{CRH}$ tissue levels (mean $\pm \mathrm{SEM}$ ) at 0 min and I h after 15 min of noise exposure at the CeA (a), MeA (b), and BLA (c). $\mathrm{CeA}$, central nucleus of the amygdala; MeA, medial nucleus of the amygdala; BLA, basal lateral nucleus of the amygdala. *, **Significant withinstrain difference from matched time control group, $p<0.02$ and $p<0.01$, respectively. ${ }^{\dagger}, "$ Significant within-strain difference from 0 -min time point, $p<0.02$ and $p<0.001$, respectively.

levels of ir-CRH in nonstressed animals were reduced relative to that of rats that had been exposed to noise or to control conditions $1 \mathrm{~h}$ earlier (see Figure 5a).

At the $\mathrm{MeA}$, ir-CRH varied as a function of the Strain $\times$ Noise interaction, $F_{(1,58)}=3.93, p<0.05$. As seen in Figure 5b, in the absence of noise the levels of ir-CRH were comparable in the two strains. The level of ir-CRH in Fischer rats was elevated both immediately and $1 \mathrm{~h}$ following exposure to noise. Immediately after noise exposure ir-CRH was increased in the MeA of Lewis rats, but this elevation was not evident $1 \mathrm{~h}$ after noise exposure. Finally, at the BLA the level of ir-CRH was greater in Lewis than in Fischer rats, $F_{(1,59)}=8.06, p<0.01$, although the magnitude of this effect was relatively small and unrelated to the stressor condition (see Figure 5c).

Variations of ir-CRH levels at other stressor-sensitive brain regions following noise exposure. The levels of ir$\mathrm{CRH}$ within the LC varied as a function of the Strain $\times$ Noise interaction, $\mathrm{F}_{(1,39)}=8.54, p<0.01$. The $t$ tests confirmed that there was no change of ir-CRH in the Lewis rats. However, while the measured levels of ir-CRH

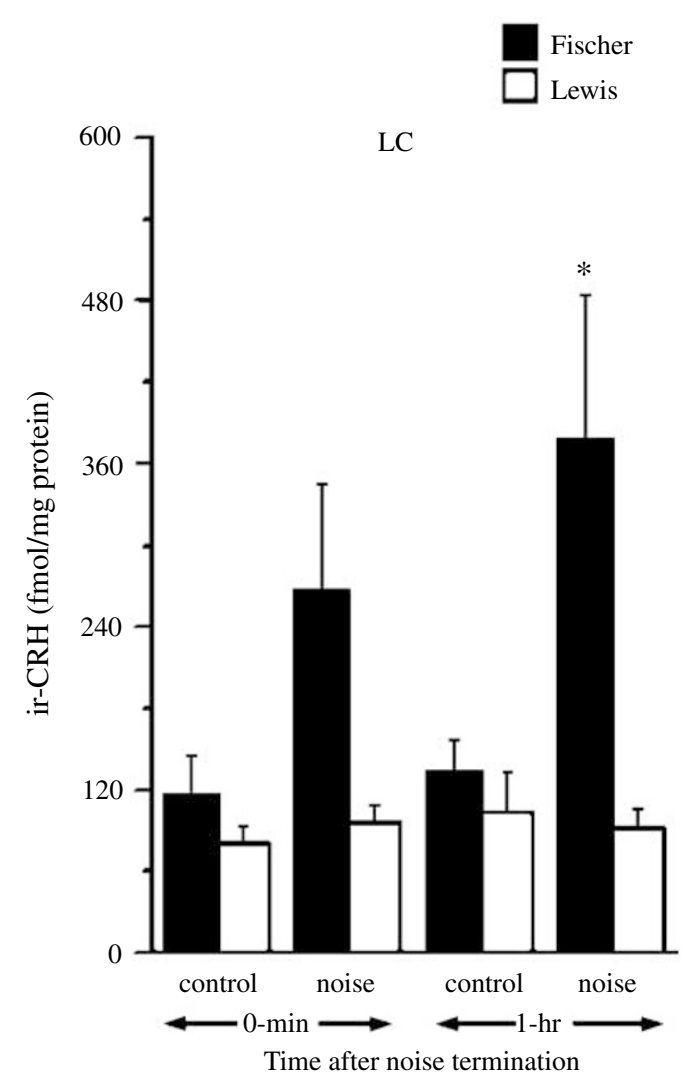

Figure 6 Variations of ir- $\mathrm{CRH}$ tissue levels (mean $\pm \mathrm{SEM}$ ) at 0 min and I $\mathrm{h}$ after $15 \mathrm{~min}$ of noise exposure at the LC. LC, locus coeruleus. *Significant within-strain difference from matched time control group, $p<0.05$.

increased appreciably at both time points in the Fischer rats, they only reached statistical significance $1 \mathrm{~h}$ after noise exposure (see Figure 6).

Noise exposure failed to alter the levels of ir-CRH at the $\mathrm{PV}$ and dHipp in either strain (data not shown); however, under control conditions Lewis rats had significantly elevated ir-CRH content at the nAcb, but reduced levels at the Cau at the 0-min time interval. Finally, at $1 \mathrm{~h}$ following noise exposure Fischer rats exhibited significant increases of ir-CRH tissue levels at the nAcb, whereas no change was observed in the Lewis rats (see Table 1).

\section{The Impact of Environmental Cues on Protracted} Changes in Brain ir-CRH and Plasma Hormone Levels $24 \mathrm{~h}$ Following Noise Exposure

Plasma ACTH, corticosterone, and prolactin levels were unaffected by noise exposure administered $24 \mathrm{~h}$ earlier, irrespective of whether the stressor was administered to rats in their home cages or in novel (distinct) environments (data not shown). Similarly, ir-CRH levels within the PVN and $\mathrm{Me}-\mathrm{Arc}$ at $24 \mathrm{~h}$ were unaffected by the environment in which the noise had been applied (data not shown). Within the CeA the level of ir-CRH $24 \mathrm{~h}$ after noise exposure varied as a function of the interaction between the Strain and the environment in which the noise was administered, $\mathrm{F}_{(1,29)}=22.51, p<0.01$. Noise applied to Lewis rats while in the home cage resulted in ir- $\mathrm{CRH}$ levels at the CeA 
Table I Variations of ir-CRH Levels at Stressor-Sensitive Brain Regions 0 min and I $\mathrm{h}$ after 15 min of Noise Exposure

\begin{tabular}{|c|c|c|c|c|c|}
\hline \multirow[b]{3}{*}{ Strain } & \multirow[b]{3}{*}{ Region } & \multicolumn{4}{|c|}{ Time after noise termination } \\
\hline & & \multicolumn{2}{|c|}{$0 \mathrm{~min}$} & \multicolumn{2}{|c|}{ I h } \\
\hline & & Control & Noise & Control & Noise \\
\hline Fischer & $\begin{array}{l}\text { nAcb } \\
\text { Cau } \\
\text { PFC }\end{array}$ & $\begin{array}{c}51.4 \pm 9.1 \\
57.8 \pm 4.5 \\
668.3 \pm 31.9\end{array}$ & $\begin{array}{c}94.8 \pm 19.2 \\
45.9 \pm 3.5 \\
717.2 \pm 84.4\end{array}$ & $\begin{array}{c}62.9 \pm 18.9 \\
46.2 \pm 2.7^{\dagger} \\
420.6 \pm 67.6^{\dagger \dagger}\end{array}$ & $\begin{array}{c}130.8 \pm 19.4 * \\
52.3 \pm 4.9 \\
414.4 \pm 55.9^{\dagger}\end{array}$ \\
\hline Lewis & $\begin{array}{l}\text { nAcb } \\
\text { Cau } \\
\text { PFC }\end{array}$ & $\begin{array}{c}134.1 \pm 28 .\left.\right|^{\$ \S} \\
39.4 \pm 2.9^{\$ \S} \\
528.8 \pm 62.9\end{array}$ & $\begin{array}{c}85.6 \pm 18.3 \\
41.0 \pm 5.7 \\
521.5 \pm 49.2\end{array}$ & $\begin{array}{r}70.9 \pm 11.7 \\
52.5 \pm 5.2 \dagger \\
400.5 \pm 25.1\end{array}$ & $\begin{array}{c}72.2 \pm 10.5^{\S} \\
41.9 \pm 4.9 \\
515.8 \pm 43.3^{*}\end{array}$ \\
\hline
\end{tabular}

*, ** Significant within-strain difference from same time control condition. ${ }^{\dagger}{ }^{\dagger \dagger}$ Significant within-strain difference from 0 min after noise termination. ${ }^{\S}{ }^{\S}$ Significant between-strain difference. All effects are $p<0.05$ and $p<0.02$, respectively. Data are presented as fmol/mg protein (Mean \pm SEM).

Caudate (Cau), paraventricular thalamic nucleus (PV), nucleus accumbens (nAcb), prefrontal cortex (PFC), and dorsal hippocampus (dHipp).

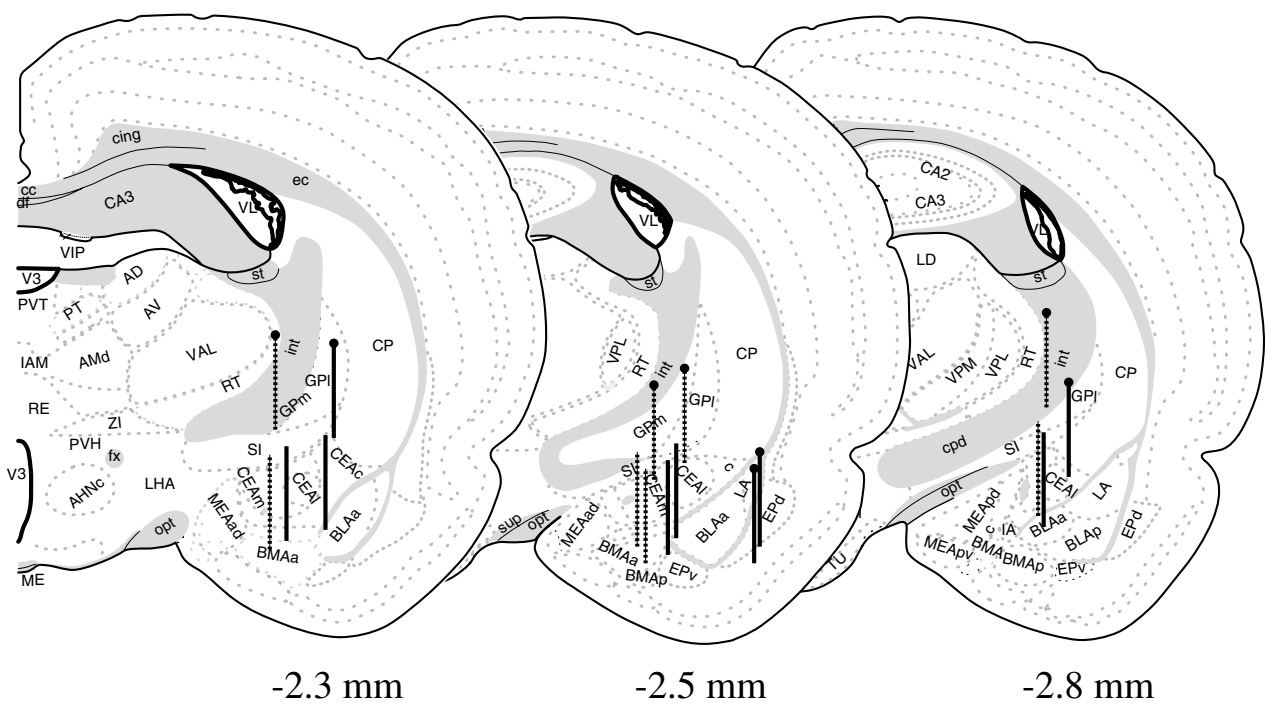

Figure 7 Anatomical localization of the microdialysis probe membranes aimed at the central nucleus of the amygdala in animals exposed to noise. A series of consecutive brain sections bearing the trace of microdialysis probes were stained, the most ventral location of the probe tip was determined, and a $2.0 \mathrm{~mm}$ line was drawn vertically, tracing the estimated location of the active region of the probe. Solid and dashed vertical lines represent Fischer and Lewis rats, respectively, included in the analyses. Pin-head traces represent their corresponding 'off-site' placements omitted from the overall analyses.

exceeding that of similarly treated Fischer rats and Lewis rats exposed to noise in the novel cage (respective means: $325 \pm 33$ vs $199 \pm 12$ vs $192 \pm 12$ ). Finally, there was a tendency towards higher ir-CRH levels in Fischer rats exposed to noise in the novel cage compared to their homecage counterparts; however, this difference was not statistically significant (respective means, $247 \pm 13$ vs $199 \pm 12$ ).

In the remaining brain regions (MeA, BLA, dHipp, PFC, nAcb, Cau, and PV), the exposure environment had no effect on the levels of ir-CRH $24 \mathrm{~h}$ after the noise exposure (data not shown).

\section{The Effect of Noise Exposure on the Release of ir-CRH from the $\mathrm{CeA}$}

Figure 7 depicts the histological verification of the microdialysis probe placements. An initial comparison of the raw ir-CRH values from the dialysates constituting the baselines from animals with correctly positioned probes ( $n=5 /$ Fischer; $n=4 /$ Lewis) revealed a significant difference between the two strains (respective means; $19.2 \pm 5.2$ and $217.3 \pm 17.5 \mathrm{pg} / 45 \mu \mathrm{l}, p<0.0001)$. An ANOVA of the percent change from baseline revealed that interstitial ir-CRH varied as a function of Sample, $\mathrm{F}_{(12,84)}=14.95, p<0.001$. Post hoc analyses revealed that noise exposure was associated with an immediate (during noise exposure) rise of ir-CRH concentration in the dialysates collected from the Fischer rats, which persisted until the end of the collection period (see Figure 8). In the Lewis rats ir-CRH levels increased during noise exposure but did not reach statistical significance $(p=0.06)$ until the third postnoise sample. Thereafter, ir-CRH concentrations were significantly higher than baseline values until the end of the experiment (see Figure 8). Further, between-group comparisons at each sample time confirmed that although ir-CRH in the Lewis 


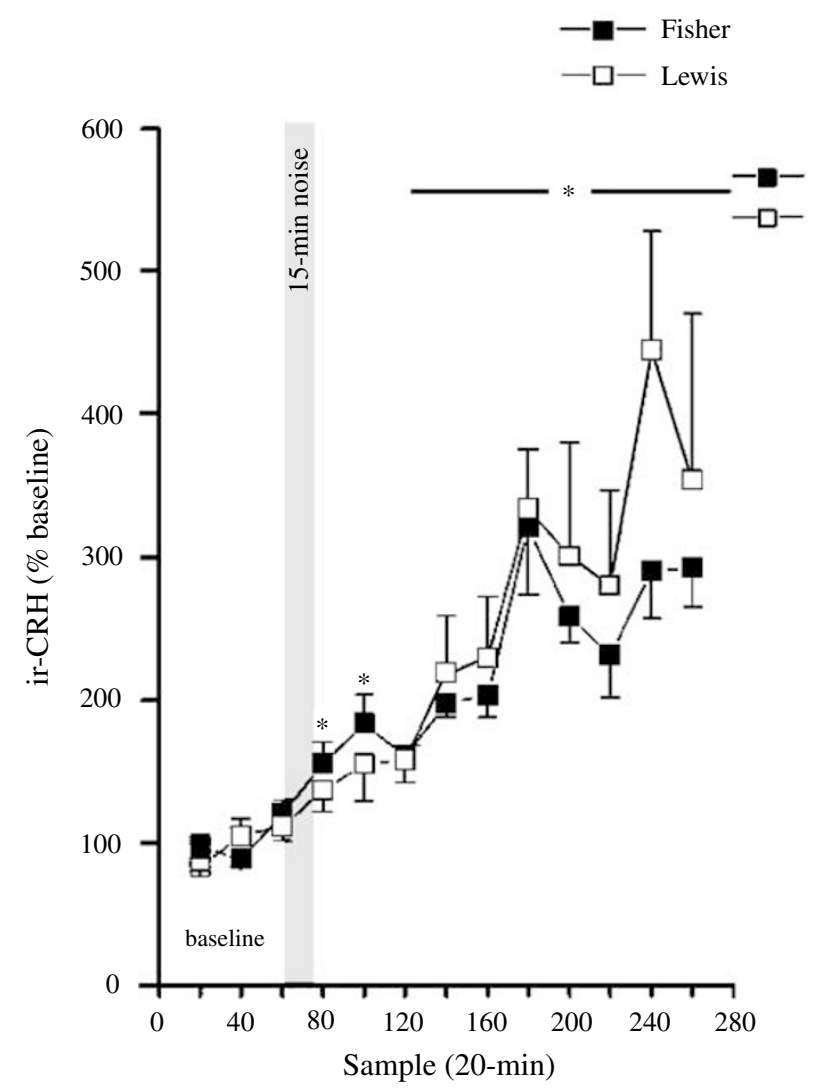

Figure 8 Levels of ir- $\mathrm{CRH}$ at the $\mathrm{CeA}$ as measured by in vivo microdialysis under baseline condition and following 15 min of noise exposure in Fischer and Lewis rats. The baseline samples from each subject were averaged and defined as 100\%. All values were then expressed as a percent of that baseline (actual values were $4.04 \pm 1.1$ and $45.7 \pm 3.7 \mathrm{fmol} / \mathrm{sample}$, for Fischer and Lewis strains, respectively). *Significant difference from baseline condition at $p<0.05$.

strain was elevated relative to that seen in Fischer rats, this difference was not statistically significant.

\section{The Effect of Noise Exposure on ir-CRH and Corticosterone Availability at the Anterior Pituitary}

Figure 9 (top panel insert) depicts the typical probe placement within the anterior pituitary. The variability in push-pull probe placement within the anterior pituitary was visually assessed in freshly extracted whole pituitary glands under low-level magnification. The assessment of probe placement was readily apparent in this manner. With the exception of a single Fischer rat, all probes were correctly positioned at the anterior pituitary gland. An initial comparison of the raw ir-CRH values from the perfusates constituting the baselines from animals with correctly positioned probes ( $n=11 /$ Fischer; $n=9 /$ Lewis) revealed no strain differences (respective means; $29.9 \pm 4.3$ and $21.5 \pm 2.5 \mathrm{pg} / 45 \mu \mathrm{l}, p=0.4$ ). An ANOVA of the percent change from baseline revealed a significant Sample $\times$ Strain interaction, $\mathrm{F}_{(17,323)}=2.92, p<0.001$. Post hoc analyses indicated that during the first $10 \mathrm{~min}$ of the 15 -min noise exposure, ir-CRH concentrations were significantly elevated above baseline in the Fischer rats $(p$ 's $<0.05)$ and decreased

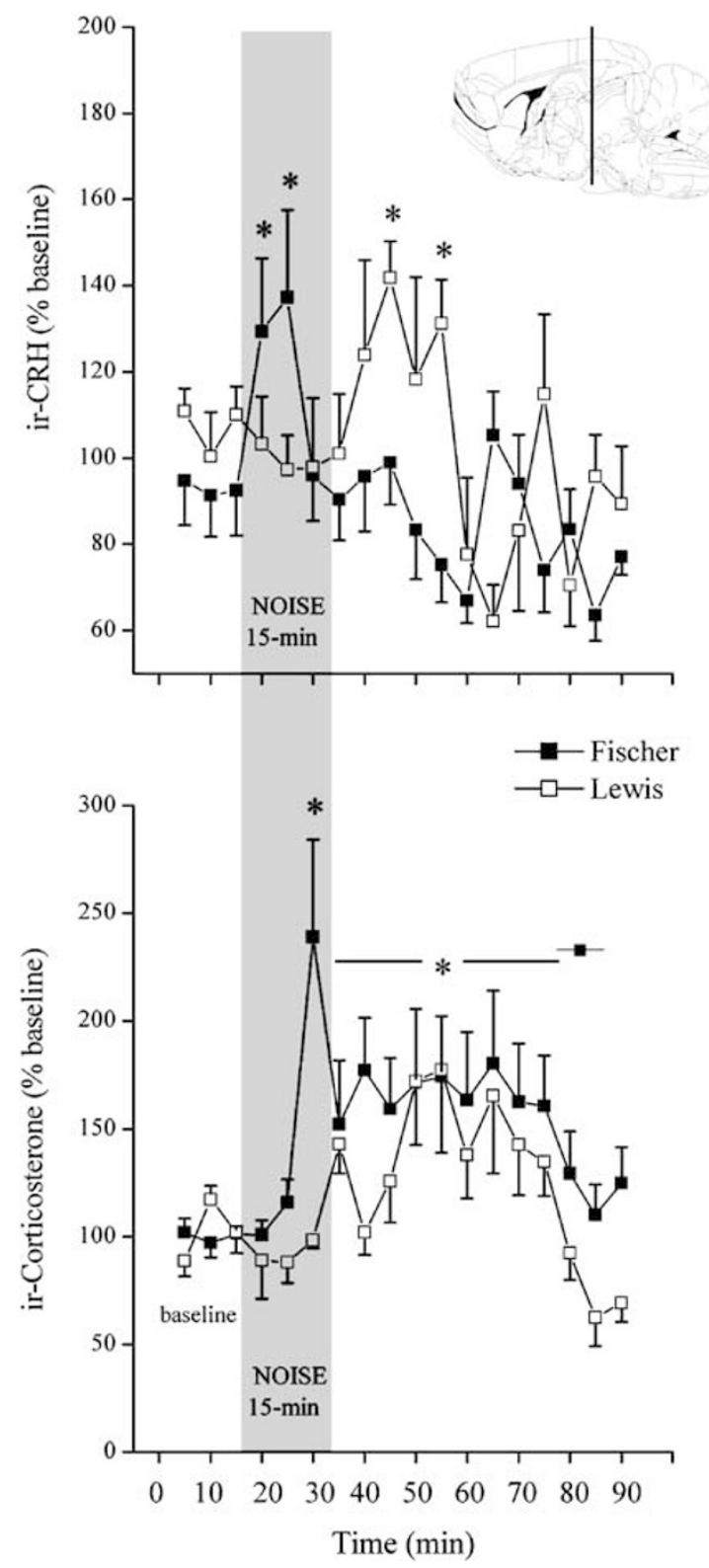

Figure 9 Levels of ir- $\mathrm{CRH}$ at the anterior pituitary gland (top panel) and corticosterone (bottom panel) as measured by in vivo push-pull perfusion under baseline condition and following 15 min of noise exposure in Fischer and Lewis rats. The baseline samples from each subject were averaged and defined as 100\%. All values were then expressed as a percent of that baseline (actual ir-CRH values were $6.3 \pm 0.9$ and $4.5 \pm 0.5 \mathrm{fmol} / \mathrm{sample}$, for Fischer and Lewis strains, respectively and corticosterone values were $8.7 \pm 0.9$ and $4.0 \pm 0.6 \mathrm{fmol} / \mathrm{sample}$, respectively). *Significant difference from baseline condition at $p<0.05$.

thereafter to basal levels (see Figure 9, top panel). In the Lewis rats, noise was associated with a more delayed rise of ir-CRH concentrations, beginning at $25 \mathrm{~min}$ following noise onset, and reaching a statistically significant increase above baseline by $30 \mathrm{~min}(p<0.01)$. The ir-CRH remained elevated until about $45 \mathrm{~min}$ following stressor onset, and then declined (see Figure 9, top panel).

An initial comparison of the means constituting the baselines for both strains revealed that corticosterone levels in the perfusates collected from the Fischer rats were 
significantly higher than those of the Lewis rats (respective means; $3.0 \pm 0.3$ and $1.4 \pm 0.2 \mathrm{pg} / 45 \mu \mathrm{l}, p<0.05$ ). The levels of corticosterone varied as a function of the Sample, $\mathrm{F}_{(17,272)}=3.83, p<0.0001$. During the last $5 \mathrm{~min}$ of the 15 min noise exposure, corticosterone levels were significantly elevated in the Fischer rats and remained so for an additional nine samples ( $45 \mathrm{~min}$ ) (see Figure 9, bottom panel). In the Lewis strain noise exposure failed to increase significantly corticosterone levels in the perfusates. However, by the eighth postnoise sample ( $40 \mathrm{~min}$ postonset), corticosterone levels were elevated and approached statistical significance $(p=0.07)$ (see Figure 9 , bottom panel).

\section{DISCUSSION}

The present study demonstrated that relative to male Lewis rats, Fischer rats exhibited a more robust corticosterone and ACTH response to noise exposure. This is concordant with earlier reports using female rats (Windle et al, 1998) and suggests that enhanced HPA reactivity of the Fischer rat (as compared to Lewis) is gender independent. While noise did not increase plasma corticosterone in Lewis rats in the present investigation, certain other stressors, including saline injection and restraint, have been reported to increase plasma corticosterone in both strains, although this effect was blunted and transient in the Lewis rats (Baumann et al, 2000; Stohr et al, 2000). It is possible that under our sampling schedule (immediately, 1 and $24 \mathrm{~h}$ postexposure) noise-induced changes of ACTH and corticosterone went undetected in the Lewis rats. However, as ACTH peaks earlier than corticosterone following stressor exposure, it seems rather unlikely that we would have failed to detect changes in either of these hormones, particularly 15 min after stressor onset.

Consistent with elevated circulating corticosterone levels following noise exposure, marked strain differences were evident with respect to interstitial levels of corticosterone at the anterior pituitary, with noise exposure markedly elevating corticosterone availability in the Fischer, but not in the Lewis rats. Corticosterone-induced suppression of the HPA axis occurs both at pituitary and suprapituitary levels (Mahmoud et al, 1984; Widmaier and Dallman, 1984). The finding that male Fischer and Lewis rats display similar sensitivity to peripherally administered dexamethasone (Gomez et al, 1998) suggests similar glucocorticoid receptor function between these strains. Thus, the possibility that the elevated corticosterone binding globulin observed in Fischer relative to Lewis rats (Dhabhar et al, 1993) hinders this hormone from accessing the central target(s) involved in the inhibition of the HPA axis should be considered. In contrast to the strain-dependent effects of the stressor on ACTH and corticosterone, noise exposure was associated with a comparable increase of plasma prolactin in both strains. Most stressors inhibit the activity of tuberoinfundibular dopamine neurons in the arcuate nucleus, thus disinhibiting the release of prolactin from the anterior pituitary (Freeman et al, 2000). Thus, the blunted ACTH and corticosterone responses in Lewis rats are likely attributable to central mechanisms that specifically trigger the activation of the HPA axis in response to stressful stimuli and not to strain-specific differences of stressor perception. Indeed, the more pronounced freezing observed in the Lewis strain suggests that their auditory perception was not impaired. However, to our knowledge data are unavailable assessing differences in auditory acuity between these two rat strains.

Noise exposure was associated with site-specific alterations of tissue ir-CRH concentrations in Fischer and Lewis rats at the LC, PVN, and Me-Arc as well as in other related limbic structures, such as the amygdala. The regionally distinct effects may be related to several factors, including (a) whether the region comprises cell bodies (CeA and $\mathrm{PVN}$ ) or terminal regions (LC and $\mathrm{Me}-\mathrm{Arc}$ ) and (b) regionspecific differential turnover rates, that is, changes in the level of the peptide could reflect the combined effects of utilization as well as the rate of replenishment. Accordingly, changes in the peptide levels at these regions ought to be interpreted cautiously and, as indicated earlier, in vivo dynamic assessments are fundamental in order to delineate the processes related to $\mathrm{CRH}$ variations. In the Fischer rats, and to a lesser extent in the Lewis strain, the content of ir$\mathrm{CRH}$ at the PVN $15 \mathrm{~min}$ following noise onset was elevated compared to control conditions. By $1 \mathrm{~h}$ following noise exposure, ir-CRH levels were lower in both strains compared to the control levels; however, at this time control levels of ir-CRH were greater than that seen in control animals $1 \mathrm{~h}$ earlier. One possible interpretation for this pattern of change might be that both the noise exposure and control conditions (which entailed transportation of rats to the test room) imparted changes of PVN ir-CRH content, but that these changes were more persistent in rats exposed to noise. While efforts were made to minimize the potential effects associated with the transportation of the animals to the test area (ie exposing animals to daily transportation to and from the experimental test room, for over 3 weeks), it seems that CRH variations at the PVN were still evident in response to potential situational variables. Furthermore, one cannot discount the possibility that other factors, such as the potential interaction between time since stressor exposure and the animal's response to handling, may have influenced peptide tissue levels. Similarly, although efforts were made to minimize diurnal fluctuations of CRH by maintaining a narrow temporal testing window, this does not eliminate the potential peptidergic fluctuations that may occur within this time frame (Ixart et al, 1993). Likewise, Windle et al (1998) have recently demonstrated that the pulsatile release of plasma corticosterone is not only different between female Fischer and Lewis rats, but that noise exposure only evoked an increase in plasma corticosterone in the Lewis rats if the stressor coincided with the increasing phase of endogenous corticosterone release. In contrast, the Fischer rats responded with a surge of corticosterone irrespective of the directional phase of corticosterone at the time of noise exposure. These results suggest that stressor-induced changes could be undermined or exaggerated depending on the specific sampling time. In addition, it ought to be considered that experimental conditions, in general, may have influenced the extent of the strain and stressor effects observed in the present investigation. For instance, stressed and control animals were housed in the same room and the possibility exists that olfactory cues and/or ultrasonic vocalizations of stressed rats could have influenced the control animals. 
As alluded to earlier, tissue peptide release or utilization can change without peptide levels being altered, as increased release may be accompanied by an equal rate of synthesis, which would not be detected in post-mortem analyses of tissue peptide levels. Thus, the use of in vivo sampling techniques has distinct advantages in detecting potential strain differences with respect to the impact of various challenges. The current study represents the only direct assessment of noise-associated alterations in the availability of ir- $\mathrm{CRH}$ at the anterior pituitary in the Fischer and Lewis rats. Push-pull perfusion at the anterior pituitary revealed that while noise exposure provoked a rapid rise of interstitial ir-CRH levels in Fischer rats, this change was delayed in Lewis rats. It might have been expected that since ir-CRH availability increased at all in Lewis rats, plasma corticosterone should likewise have increased. In fact, the rise of corticosterone availability in the Lewis rats appeared to follow the delayed rise of ir-CRH; nevertheless, this blunted increase failed to reach statistical significance. Accordingly, other factors that might influence the stimulatory effect of $\mathrm{CRH}$ on ACTH release should be considered. It is of interest that cultured pituitary cells taken from female Lewis rats are reportedly more sensitive to the suppression of CRH-induced secretion of ACTH by dexamethasone and corticosterone (Zelazowski et al, 1992). It might thus be argued that corticosterone availability at the anterior pituitary in Lewis rats does not need to reach the same concentrations as it does in the Fischer rats in order to inhibit further activation of the HPA axis. This contention is consistent with the finding that, in males, central administration of dexamethasone blunts cocaine-induced corticosterone secretion to a greater extent in the Lewis than in the Fischer rat (Simar et al, 1997).

Several stressors, including noise, increase the neuronal firing rate and release of various neurotransmitters at the LC (Singewald et al, 1999; Singewald and Philippu, 1998). To date, the release of CRH at the LC has been alluded to, but never directly measured. Nevertheless, several indirect approaches support the hypothesis that CRH may serve as an excitatory neurotransmitter at this site (Valentino et al, 1998; Valentino and Wehby, 1988; Van Bockstaele et al, 1996, 1998). In the current study, we report that noise exposure was associated with elevated ir-CRH tissue content at the LC among Fischer rats, but not in the Lewis strain. If lower tissue peptide levels in the Lewis rats reflect enhanced release, then it would be consistent with the finding that in vitro firing rate of LC neurons is greater in the Lewis as compared to the Fischer rats (Guitart et al, 1993). Ultimately, it will be necessary to assess stressor provoked in vivo $\mathrm{CRH}$ release at the LC in the two rat strains.

Considerable efforts have been made towards characterizing the role of the amygdala in the cognitive, behavioral, and physiological responses to emotionally salient stimuli (Feldman et al, 1994; Kalin et al, 2001; Swanson and Petrovich, 1998), including noise (Galeno et al, 1984). The current micropunch data suggest nucleus- and peptidespecific alterations at the amygdaloid complex. Immediately after noise exposure a marked elevation of ir-CRH was evident at the MeA in both strains, while no differences were noted between the control and noise-exposed groups at either the CeA or the BLA. These data appear to support the proposition that the MeA is more closely aligned with the generation of the neuroendocrine response to emotional stressors, relative to either the CeA or the BLA (Dayas et al, 1999). However, ir-CRH tissue levels at the CeA $1 \mathrm{~h}$ following control conditions (which included transport to and from the test room) was markedly reduced in comparison with the control group killed at the earlier time interval. Furthermore, ir-CRH levels at the CeA taken from animals killed at 1-h poststressor exposure were similar to both control and noise-exposed groups killed at the 15-min sampling time. At this juncture, it is difficult to discern why higher CRH levels at the PVN are evident in control rats $1 \mathrm{~h}$ after exposure to control conditions, while in the CeA the CRH levels were reduced in the same group of animals. One possibility is that the transportation of the rats to the test area acted as a mild stressor, but still sufficient to influence amygdaloid ir-CRH at the earlier sampling time, after which the peptide reverted to prestress levels. In contrast, with the more severe noise stressor the elevated peptide levels were more persistent. The finding that the profiles in the PVN and CeA were opposite of one another may be related to the fact that PVN CRH turnover is particularly rapid and consequently replenishment of the peptide levels is not evident at short intervals following a stressor experience. Indeed, it is not unusual for stressors not to alter PVN CRH levels despite the fact that these treatments are associated with elevated pituitary ACTH and adrenomedullary glucocorticoid release (Makino et al, 1999, 1994).

The results from the microdialysis study support the notion that the $\mathrm{CeA}$ is involved in noise stressor reactivity (Galeno et al, 1984), as the concentration of ir-CRH in the dialysates collected from the CeA increased following noise exposure in both strains. This is consistent with reports that microinjections of CRH into the CeA decreased immobility, but increased exploration and rearing (Wiersma et al, 1997, 1995), whereas CRH receptor antagonists attenuated behaviors associated with stressors, including freezing (Swiergiel et al, 1993).

The observed behavioral response to noise exposure in the present study was very similar to that reported by Windle et al (1998) where female Fischer and Lewis rats displayed striking differences in their behavioral response to loud noise. We noted that, in general, the Fischer rats displayed a more active coping style (increased exploration and grooming), whereas the Lewis strain adopted a more defensive coping strategy (freezing). It was likewise reported that in a forced swim test, the Fischer rats struggled more and showed less immobility than their Lewis counterparts (Lahmame et al, 1997). Interestingly, in the current study extracellular levels of $\mathrm{CRH}$ at the CeA in the Lewis rats were approximately 10 -fold greater than in the Fischer strain. Although this finding is based on a small number of animals, and hence should be regarded as provisional, it is possible that these basal differences of $\mathrm{CRH}$ might be related to the observed strain differences in the behavioral response to noise. In spite of the basal differences, upon noise exposure both strains showed a similar CRH release profile at the CeA suggesting that it is not the relative release of $\mathrm{CRH}$ at the $\mathrm{CeA}$ that subserves the behavioral response to noise. Lahmame et al (1997) likewise concluded that there was a dissociation between $\mathrm{CRH}$ 
activity (based on tissue content) and the expression of depression-like behavior in the forced swim test.

The apparent disparity between $\mathrm{CRH}$ alterations and behavioral responses suggests that either the diverse behavioral profiles may reflect (1) equivalent anxiety, but expressed in a strain-dependent fashion, (2) that $\mathrm{CRH}$ at the $\mathrm{CeA}$ is not a contributing factor in the behavioral response to the noise stressor, or (3) that the sensitivity to $\mathrm{CRH}$ varies between the two strains. The latter possibility is supported by the finding that the Fischer and Lewis rats show behavioral differences in response to centrally applied CRH (Glowa et al, 1991), such that exogenously administered $\mathrm{CRH}$ makes the Fischer rats behaviorally similar to non-CRH-exposed Lewis rats. Indeed, female Fischer rats show an immediate rise of plasma corticosterone following centrally applied $\mathrm{CRH}$, compared to the relatively delayed increase observed in female Lewis rats (Windle et al, 1998). Likewise, it has been demonstrated that female Fischer rats are more sensitive to $\mathrm{CRH}$-induced ACTH augmentation than Lewis rats (Spinedi et al, 1994). These findings, taken together with the strain differences we observed in both $\mathrm{CRH}$ and corticosterone availability at the anterior pituitary gland, suggest that at least one of the underlying mechanisms mediating the strain differences may be related to the apparent strain-dependent sensitivity to the effects of $\mathrm{CRH}$, which would then impact stressor-associated HPA activation and behavioral change (Berridge and Dunn, 1989).

In summary, the current neurochemical, neuroendocrine, and behavioral data provide evidence that the apparent hypoadrenal response in the Lewis rats exposed to stressors (noise in this instance) is not simply a function of altered $\mathrm{CRH}$ release, but may have more to do with altered sensitivity at the receptor and postreceptor level. In this regard, the strain differences reported here, as well as by others (Glowa et al, 1991; Gomez et al, 1998; Windle et al, 1998), may be reflective of strain differences in the number and/or sensitivity of pituitary corticotrophs to endogenous $\mathrm{CRH}$ and/or glucocorticoids, as suggested by in vitro findings in females of these strains (Zelazowski et al, 1992). Our results also make it tempting to suggest that noise exposure might have protracted effects on $\mathrm{CRH}$ changes related to the exposure environment and that Lewis rats might be more sensitive to these cues compared to Fischer rats. Such findings, along with those that suggest that stressors might sensitize processes associated with neurotransmitter release (Berridge and Dunn, 1989; Zhang et al, 1995) or alter co-expression of neuropeptides within hypothalamic neurons (Bartanusz et al, 1993; Schmidt et al, 1996), indicate that aversive events, such as environmental noise exposure, may have long-term repercussions that could impact on behavioral outputs. However, it is likely that the impact of such events may be dependent on individual characteristics, including genetic disposition.

The present investigation makes it clear that a noise stressor profoundly influences corticosterone and ACTH release and may affect neuropeptide activity at hypothalamic and extrahypothalamic sites. Moreover, among the Lewis rats, ir-CRH changes at the CeA were evident as long as $24 \mathrm{~h}$ after the stressor experience, provided that the animals were housed in the environment where the stressor had been applied. The data further indicate that the wellcharacterized corticosterone and ACTH responses to stressors in Fischer and Lewis rats were also evident with respect to ir- $\mathrm{CRH}$ availability at the anterior pituitary and, to a lesser extent, release at the CeA. Finally, it appeared that a mismatch existed between behavioral coping responses and the neuroendocrine alterations in these strains; while the Fischer rat reacts to stressors with active responses, the Lewis rats assumed a passive defensive strategy in response to noise.

\section{ACKNOWLEDGMENTS}

Assistance of Dr L Whitehurst and M Truong in manuscript preparation is greatly appreciated. Funding from CIHR and Health Canada supported this research.

\section{REFERENCES}

Anisman H, Lacosta S, Kent P, McIntyre DC, Merali Z (1998). Stressor-induced corticotropin-releasing hormone, bombesin, ACTH and corticosterone variations in strains of mice differentially responsive to stressors. Stress 2: 209-220.

Anisman H, Zalcman S, Shanks N, Zacharko RM (1991). Multisystem regulation of performance deficits induced by stressors: an animal model of depression. In: Boulton A, Baker G, MartinIverson M (eds). Neuromethods, Vol. 19: Animal Models of Psychiatry, II. Humana Press: Totowa, NJ. pp 1-59.

Bartanusz V, Jezova D, Bertini LT, Tilders FJ, Aubry JM, Kiss JZ (1993). Stress-induced increase in vasopressin and corticotropin-releasing factor expression in hypophysiotrophic paraventricular neurons. Endocrinology 132: 895-902.

Baumann MH, Elmer GI, Goldberg SR, Ambrosio E (2000). Differential neuroendocrine responsiveness to morphine in Lewis, Fischer 344, and ACI inbred rats. Brain Res 858: 320-326.

Berridge CW, Dunn AJ (1989). Restraint-stress-induced changes in exploratory behavior appear to be mediated by norepinephrinestimulated release of CRF. J Neurosci 9: 3513-3521.

Bonsall RW, Weiss F (1996). Corticosterone levels in rat brain microdialysates following exposure to noise stress or to lipopolysaccharide. Soc Neurosci Abstr 22: 453.

Dayas CV, Buller KM, Day TA (1999). Neuroendocrine responses to an emotional stressor: evidence for involvement of the medial but not the central amygdala. Eur J Neurosci 11: 2312-2322.

Dhabhar FS, McEwen BS, Spencer RL (1993). Stress response, adrenal steroid receptor levels and corticosteroid-binding globulin levels - a comparison between Sprague-Dawley, Fischer 344 and Lewis rats. Brain Res 616: 89-98.

Dhabhar FS, McEwen BS, Spencer RL (1997). Adaptation to prolonged or repeated stress - comparison between rat strains showing intrinsic differences in reactivity to acute stress. Neuroendocrinology 65: 360-368.

Dhabhar FS, Miller AH, McEwen BS, Spencer RL (1995). Differential activation of adrenal steroid receptors in neural and immune tissues of Sprague-Dawley, Fischer 344, and Lewis rats. J Neuroimmunol 56: 77-90.

Feldman S, Conforti N, Itzik A, Weidenfeld J (1994). Differential effect of amygdaloid lesions on CRF-41, ACTH, and corticosterone responses following neural stimuli. Brain Res 658: 21-26.

Freeman ME, Kanyicska S, Lerant A, Nagy G (2000). Prolactin: structure, function, and regulation of secretion. Physiol Rev 80: 1523-1631.

Galeno TM, VanHoesen GW, Brody MJ (1984). Central amygdaloid nucleus lesion attenuates exaggerated hemodynamic responses to noise stress in the spontaneously hypertensive rat. Brain Res 291: 249-259. 
Glowa JR, Sternberg EM, Gold PW (1991). Differential behavioral response in LEW/N and F344/N rats: effects of corticotropin releasing hormone. Prog Neuropsychopharmacol Biol Psychiatry 18: $549-560$.

Goldstein LE, Rasmusson AM, Bunney BS, Roth RH (1996). Role of the amygdala in the coordination of behavioral, neuroendocrine, and prefrontal cortical monoamine responses to psychological stress. J Neurosci 16: 4787-4798.

Gomez F, DeKloet ER, Armario A (1998). Glucocorticoid negative feedback on the HPA axis in five inbred rat strains. Am J Physiol Regul Integr Comp Physiol 274: R420-R427.

Guitart X, Kogan JH, Berhow M, Terwilliger RZ, Aghajanian GK, Nestler EJ (1993). Lewis and Fischer rat strains display differences in biochemical, electrophysiological and behavioral parameters: studies in the nucleus accumbens and locus coeruleus of drug naive and morphine-treated animals. Brain Res 611: 7-17.

Horvitz JC, Williams G, Joy R (2001). Time-dependent actions of $\mathrm{D}_{2}$ family agonist quinpirole on spontaneous behavior in the rat: dissociation between sniffing and locomotion. Psychopharmacology 154: 350-355.

Hsu DT, Chen F-L, Takahashi LK, Kalin NH (1998). Rapid stressinduced elevations in corticotropin-releasing hormone mRNA in rat central amygdala nucleus and hypothalamic paraventricular nucleus: an in situ hybridization study. Brain Res 788: 305-310.

Ixart G, Siaud P, Barbanel G, Mekaouche M, Givalois L, Assenmacher I (1993). Circadian variations in the amplitude of corticotropin-releasing hormone 41 (CRH41) episodic release measured in vivo in male rats: correlations with diurnal fluctuations in hypothalamic and median eminence CRH41 contents. J Biol Rhythms 8: 297-309.

Kalin NH, Shelton SE, Davidson RJ, Kelley AE (2001). The primate amygdala mediates acute fear but not the behavioral and physiological components of anxious temperament. J Neurosci 21: 2067-2074.

Lahmame A, Grigoriadis DE, DeSouza EB, Armario A (1997). Brain corticotropin-releasing factor immunoreactivity and receptors in five inbred rat strains: relationship to forced swimming behaviour. Brain Res 750: 285-292.

Mahmoud SN, Scaccianoce S, Scraggs PR, Nicholson SA, Gillham B, Jones MT (1984). Characteristics of corticosteroid inhibition of adrenocorticotrophin release from the anterior pituitary gland of the rat. J Endocrinol 102: 33-42.

Maidment NT, Evans CT (1991). Measurement of extracellular neuropeptides in the brain: microdialysis linked to subfemptomole limits of detection. In: Robinson TE, Justice JB (eds). Microdialysis in the Neurosciences. Amsterdam: Elsevier. pp 275-303.

Makino S, Gold PW, Schulkin J (1994). Effects of corticosterone on CRH mRNA and content in the bed nucleus of the stria terminalis; comparison with the effects in the central nucleus of the amygdala and the paraventricular nucleus of the hypothalamus. Brain Res 19: 141-149.

Makino S, Shibasaki T, Yamauchi N, Nishioka T, Mimoto T, Wakabayashi I et al (1999). Psychological stress increased corticotropin-releasing hormone mRNA and content in the central nucleus of the amygdala but not in the hypothalamic paraventricular nucleus in the rat. Brain Res 850: 136-143.

Mason D, MacPhee I, Antoni F (1990). The role of the neuroendocrine system in determining genetic susceptibility to experimental allergic encephalomyelitis in the rat. Immunology 70: $1-5$.

Merali Z, Banks K (1994). Does the histaminergic system mediate bombesin/GRP-induced suppression of food intake. $A m \mathrm{~J}$ Physiol Regul Intergr Comp Physiol 267: R1589-R1595.

Merali Z, Kent P, Michaud DS, McIntyre DC, Anisman H (2001). Differential impact of predator or immobilization stressors on central corticotropin-releasing hormone and bombesin-like peptides in Fast and Slow seizing rats. Brain Res 906: 60-73.

Merali Z, McIntosh J, Kent P, Michaud D, Anisman H (1998). Aversive and appetitive events evoke the release of corticotropin-releasing hormone and bombesin-like peptides at the central nucleus of the amygdala. J Neurosci 18: 4758-4766.

Moghaddam B, Bunney BS (1989). Ionic composition of microdialysis perfusing solution alters the pharmacological responsiveness and basal outflow of striatal dopamine. J Neurochem 53 : 652-654.

Moncek F, Kvetnansky R, Jezova D (2001). Differential responses to stress stimuli of Lewis and Fischer rats at the pituitary and adrenocortical level. Endocr Res 35: 35-41.

Palkovits M, Brownstein MJ (1988). Maps and Guide to Microdissection of the Rat Brain. Elsevier: New York.

Paxinos G, Watson C (1986). The Brain in Stereotaxic Coordinates. Academic: New York.

Pich EM, Lorang M, Yeganeh M, Rodriguez de Fonseca F, Raber J, Koob GF et al (1995). Increase of extracellular corticotropinreleasing factor-like immunoreactivity levels in the amygdala of awake rats during restraint stress and ethanol withdrawal as measured by microdialysis. J Neurosci 15: 5439-5447.

Richter RM, Zorrilla EP, Basso AM, Koob GF, Weiss F (2000). Altered amygdalar CRF release and increased anxiety-like behavior in Sardinian alcohol-preferring rats: a microdialysis and behavioral study. Alcohol Clin Exp Res 24: 1765-1772.

Schmidt ED, Binnekade R, Janszen AW, Tilders FJ (1996). Short stressor induced long-lasting increases of vasopressin stores in hypothalamic corticotropin-releasing hormone ( $\mathrm{CRH}$ ) neurons in adult rats. J Neuroendocrinol 8: 703-712.

Simar MR, Saphier D, Goeders NE (1997). Dexamethasone suppression of the effects of cocaine on adrenocortical secretion in Lewis and Fischer rats. Psychoneuroendocrinology 22: 141153.

Singewald N, Kaehler ST, Philippu A (1999). Noradrenaline release in the locus coeruleus of conscious rats is triggered by drugs, stress and blood pressure changes. Neuroreport 10: 1583-1587.

Singewald N, Philippu A (1998). Release of neurotransmitters in the locus coeruleus. Prog Neurobiol 56: 237-267.

Spinedi E, Salas M, Chisari A, Perone M, Carino M, Gaillard RC (1994). Sex differences in the hypothalamic-pituitary-adrenal axis response to inflammatory and neuroendocrine stressors. Neuroendocrinology 60: 609-617.

Sternberg EM, Glowa JR, Smith MA, Calogero AE, Listwak SJ, Aksentijevich S et al (1992). Corticotropin releasing hormone related behavioral and neuroendocrine responses to stress in Lewis and Fischer rats. Brain Res 570: 54-60.

Sternberg EM, Hill JM, Chrousos GP, Kamilaris T, Listwak SJ, Gold PW et al (1989b). Inflammatory mediator-induced hypothalamic-pituitary-adrenal axis activation is defective in streptococcal cell wall arthritis-susceptible Lewis rats. Proc Natl Acad Sci USA 86: 2374-2378.

Sternberg EM, Young III WS, Bernardini R, Calogero AE, Chrousos GP, Gold PW et al (1989a). A central nervous system defect in biosynthesis of corticotropin-releasing hormone is associated with susceptibility to streptococcal cell wall-induced arthritis in Lewis rats. Proc Natl Acad Sci USA 86: 4771-4775.

Stohr T, Szuran T, Welzl H, Pliska V, Feldon J, Pryce CR (2000). Lewis/Fischer rat strain differences in endocrine and behavioral responses to environmental challenge. Pharmacol Biochem Behav 67: 809-819.

Swanson LW, Petrovich GD (1998). What is the amygdala? Trends Neurosci 21: 323-331.

Swiergiel AH, Takahashi LK, Kalin NH (1993). Attenuation of stress-induced behavior by antagonism of corticotropin-releasing factor receptors in the central amygdala in the rat. Brain Res 623: $229-234$. 
Vale W, Vaughan J, Yamamoto G, Bruhn T, Douglas C, Dalton D et al (1983). Assay of corticotropin releasing factor. Methods Enzymol 103: 565-577.

Valentino RJ, Curtis AL, Page ME, Pavcovich LA, Florin-Lechner SM (1998). Activation of the locus coeruleus brain noradrenergic system during stress: circuitry, consequences, and regulation. Adv Pharmacol 42: 781-784.

Valentino RJ, Wehby RG (1988). Corticotropin-releasing factor: evidence for a neurotransmitter role in the locus coeruleus during hemodynamic stress. Neuroendocrinology 48: 674-677.

VanBockstaele EJ, Colago EE, Valentino RJ (1996). Corticotropinreleasing factor-containing axon terminals synapse onto catecholamine dendrites and may presynaptically modulate other afferents in the rostral pole of the nucleus locus coeruleus in the rat brain. J Comp Neurol 364: 523-534.

VanBockstaele EJ, Colago EE, Valentino RJ (1998). Amygdaloid corticotropin-releasing factor targets locus coeruleus dendrites: substrate for the co-ordination of emotional and cognitive limbs of the stress response. J Neuroendocrinol 10: 743-757.

VandeKar LD, Piechowski RA, Rittenhouse PA, Gray TS (1991). Amygdaloid lesions: differential effect on conditioned stress and immobilization-induced increases in corticosterone and renin secretion. Neuroendocrinology 52: 89-95.

VanRaaij MT, Dobbe CJ, Elvers B, Timmerman A, Schenk E, Oortigiesen $\mathrm{M}$ et al (1997). Hormonal status and the neuroendocrine response to a novel heterotypic stressor involving subchronic noise exposure. Neuroendocrinology 65: 200-209.

WHO (1999). Guidelines for community noise. In: Berglund B, Lindvall T, Schwela DH (eds). World Health Organization, Geneva. Available at: http://www.who.int/peh/noise/guidelines2. html.
Widmaier EP, Dallman MF (1984). The effects of corticotropinreleasing factor on adrenocorticotropin secretion from perfused pituitaries in vitro: rapid inhibition by glucocorticoids. Endocrinology 115: 2368-2374.

Wiersma A, Baauw AD, Bohus B, Koolhaas JM (1995). Behavioural activation produced by CRH but not alpha-helical CRH (CRHreceptor antagonist) when microinfused into the central nucleus of the amygdala under stress-free conditions. Psychoneuroendocrinology 20: 423-432.

Wiersma A, Knollema S, Konsman JP, Bohus B, Koolhaas JM (1997). Corticotropin-releasing hormone modulation of a conditioned stress response in the central amygdala of Roman high (RHA/Verh)-avoidance and low (RLA/Verh)-avoidance rats. Behav Genet 27: 547-555.

Windle RJ, Wood SA, Lightman SL, Ingram CD (1998). The pulsatile characteristics of hypothalamo-pituitary-adrenal activity in female Lewis and Fischer rats and its relationship to differential stress responses. Endocrinology 139: 4044-4052.

Windle RJ, Wood S, Shanks N, Perks P, Conde GL, daCosta AP et al (1997). Endocrine and behavioural responses to noise stress: comparison of virgin and lactating female rats during nondisrupted maternal activity. J Neuroendocrinol 9: 407-414.

Zelazowski P, Smith MA, Gold PW, Chrousos GP, Wilder RL, Sternberg EM (1992). In vitro regulation of pituitary ACTH secretion in inflammatory disease susceptible Lewis (LEW/N) and inflammatory disease resistant Fischer (F344/N) rats. Neuroendocrinology 56: 474-482.

Zhang X, Kindel GH, Wulfert E, Hanin I (1995). Effects of immobilization stress on hippocampal monoamine release: modification by mivazerol, a new alpha 2-adrenoceptor agonist. Neuropharmacology 34: 1661-1672. 